sultant ; and their promotion will be backdated to July 1963. Others will be able to apply for promotion. Those who are unsuccessful will be placed in posts graded as medical assistant but will keep their title and their present pay, including the special allowance if they hold it. Furthermore, if the present claim for an increase in S.H.M.O. pay to $80 \%$ of consultant pay is granted by the Review Body "medical assistant" S.H.M.O.s will be paid accordingly. With the demise of their grade S.H.M.O.s may at last get their due.

The profession has accepted the new medical assistant grade with reluctance and only after insisting on stringent safeguards against its misuse. This insistence is justified from past experience of S.H.M.O.s being used to do consultant work without promotion and without consultant pay. The safeguards, if adhered to, should prove adequate for their purpose. Not so certain is whether the medical assistant grade will attract many willing recruits. Despite the intention that promotion from it to consultant rank will be possible, it is probable that the grade will be the topmost rung on the ladder for the majority who enter it. The pay will be from $£ 1,600$ to $£ 2,910$. This will not tempt many general practitioners to become part-time medical assistants, but the G.M.S. Committee is concerned ${ }^{4}$ lest the new grade may draw potential recruits away from general practice. It sees the grade as a possible solution " to a pressing hospital problem" but not as a solution to the problem of reintegrating general and hospital practice. In any event the G.M.S. Committee is not in favour of general practitioners becoming part-time medical assistants until payments for hospital work are removed from the calculation of the central pool.

Probably the proposed staffing arrangements are the best possible in the circumstances, but that is far from saying that, after 16 years, the hospital and specialist services of this country are what they should be. Action has been too little and too late. The much publicized ten-year hospital building plan turned out on examination to be a fifteen-year one, and now it looks as if it should be called a twenty-year plan. Each yearly revision seems to delay progress rather than hasten it. It has been known long enough that the hospital services would be in peril of collapse if the aid of some 4,000 overseas graduates were withdrawn. Yet only now are plans being made to increase the output of doctors. Any complacency in the face of facts such as these cannot be justified.

\section{Health at Work}

For many years the British Medical Association has been active in advocating a comprehensive industrial health service in this country, ${ }^{1-5}$ emphasizing that the future well-being of these islands is dependent on the health and welfare of all at work, whether in the factory, in the office, or on the farm. Health at Work, the latest report by the B.M.A., now published in booklet form, represents the summarized views of twenty-eight Divisions. Their purpose is primarily to maintain and improve the health of people at work, to safeguard health by ensuring safe working environments, and to suggest future lines of research in industrial health.

In 1830 Charles Thackrah's pioneer work in Leeds in industrial medicine focused attention on the relationship between health and work. Yet, as the introduction to the present booklet points out, 130 years later there is still no comprehensive health service in Britain, though working conditions have vastly improved. The enlightened lead in health matters given by nationalized and some private industrial firms has not been universally adopted. The immediate impact of this valuable report will be on smaller works (of which there are 230,000 with under 250 employees in this country). In some of them the uncoordinated efforts of many people are concerned with the problem of health, safety, or welfare-namely, personnel managers, safety officers, nursing and social workers, and trade union officials.

The opinions and suggestions expressed in the report cover many aspects of industrial health, including environmental control, the handling of toxic substances, the adolescent in industry, the problem of retirement, the disabled worker, married women in industry, accidents and their prevention, mental health in industry, and finally the role of the doctor in industry. It has not been possible to pursue any of these familiar problems in depth, but rather to focus attention on the many problems which, in the opinion of the B.M.A. Divisions, require co-ordination, urgent discussion, or immediate research.

Of particular interest is Section IX, "Accident Risk at Work." The need for initial training in accident prevention is emphasized together with continued campaigns waged in factories and supported by radio and television propaganda. The establishment of occupational health committees within works is recommended as a means of co-ordinating and improving health and welfare communications at all levels. More could be done for safety in agriculture, and a plea is made for better supervision, since tractor accidents and fatalities are frequent ; nor are the dangers of toxic chemicals sufficiently realized, for which special training is needed.

Several problems are raised in this report of which more might be said. The first is the control of environmental hazards. The majority of doctors practising in industry feel frustrated when precise environmental data cannot be supplied - for example, dust counts, noise levels, or concentration of toxic gases. It is agreed that modern hospitals cannot be run efficiently without laboratories, yet the Occupational Hygiene Centre at Slough has, most regrettably, been closed recently. It is not sufficiently realized that occupational hygiene centres are complementary to industrial health services and that the day of accepting the empiricism of "medical opinion" in industry is gone. The physical and chemical features of the environment must be known, and enlightened management will co-operate only if the facts are known. The report might have emphasized more that good work can be done only in a good environment, and the means of measuring that environment, together with accurate standards for comparison, must be available to all doctors in industry. The recent Shops, Offices and Railway Premises Act (1963) now legislating for the provision of good working conditions will mean further measurements in the fields of ventilation, temperature, and lighting. The recognition and

\footnotetext{
${ }^{1}$ Repont of Committee on Industrial Health in Factories, British Medica Association, 1941.

2 Report on a Comprehensive Occupational Health Service, British Medical Association, 1949.

3 Memorandum to Ministry of Labour and National Service on Future of Occupational Health Services, British Medical Association, 1953. - Functions of an Occupational Hygiene Service, British Medical Association, 1959.

- The Future of Occupational Health Services, British Medical Association, 1961

- Schilling, R. S. F., Proc. roy. Soc. Med., 1962, 5, 669.

7 Policy Regarding the Establishment of an Occupational Hygiene Service, British Occupational Hygiene Society, 1959.

Brit. med. $\mathcal{F}$., 1961, 2, 37.
} 
control of industrial health hazards should not depend on the ability and willingness of the employer to pay. ${ }^{67}$

Another factor worth noting is the varying degree of co-operation between industrial health services and the National Health Service. Liaison may be difficult between general practitioner, hospital consultant, and industrial medical officer, especially in those emergencies when a patient is transferred direct from factory to hospital owing to accident or illness. The acceptance of the industrial medical officer by his colleagues in general practice appears to vary in different parts of the country, and there is general agreement that services in the nationalized and the large privately owned industries have been accepted more than those in the smaller units. These prejudices are, however, gradually disappearing and mutual co-operation and understanding is now the rule.

The subject of training in industrial health, both at undergraduate and at postgraduate levels, is rightly stressed in this report, for the expansion of industrial health services requires more medical men and women trained in the specialty. Diplomas (D.I.H.) are offered at London and Dundee, and at the latter there is a certificate (C.I.H.)-a three-months course-specially catering for the general practitioners who intend to become part-time industrial medical officers or appointed factory doctors.

The special problem of the smaller factories is worth stressing, for in some of them environmental hazards are known to be high. From the pilot experiments in providing group medical services for industry at Slough, Harlow, and in Middlesex, recently extended to Rochdale and Dundee, no clear pattern for the future has yet emerged. Nevertheless, the B.M.A. together with other organizations has consistently advocated the establishment of a comprehensive industrial health service, ${ }^{8}$ statutory responsibility for which should be vested in a Government department, advised by a central occupational health service council. The report Health at Work should do much to further this aim.

\section{Elderly Diabetics}

Diabetes is a common disease. The harder it is looked for the commoner it becomes. ${ }^{1-3}$ About $\frac{1}{2}-1 \%$ of the population are known to be diabetic, and many more have the disease but do not know it-just how many depends on the methods of survey and definition of the disorder. In the course of a survey at Bedford glucose-tolerance tests were done on a random sample of the general population. The result showed a striking deterioration with age ; over the age of 70 nearly half the population had "abnormal " glucose tolerance-that is, they had blood-sugar levels two hours after taking $50 \mathrm{~g}$. of glucose of over $120 \mathrm{mg}$. per $100 \mathrm{ml}$. Thus it becomes difficult to know what significance to attach to diabetes in the elderly. If deterioration in glucose tolerance is part of ageing perhaps it is inevitable and clinically unimportant.

This is unlikely. Among people discovered in surveys to have diabetes many have symptoms (especially thirst and itching) and signs of the disease. It is a common fallacy that if the disease is " mild" (symptoms moderate, hyperglycaemia slight, and ketosis absent) its consequences are slight. Some elderly diabetics are apt to develop ketosis and will pass into coma if not promptly treated with insulin. Experience will vary from one clinic to another, but an estimate that of diabetics over the age of 60 one-third need insulin, one-third sulphonylureas, and one-third diet only is probably reasonable. If the number of patients on insulin is much higher than this it may be worth making sure that they all need it. Some elderly diabetics may have been started on insulin before the introduction of treatment by mouth and their need for it never re-examined.

If it is accepted that diabetes in the elderly is common and that early diagnosis and treatment are important, sometimes life-saving, what, if any, are the special problems of elderly diabetics? Dietary restriction, essential in the treatment of all diabetics, need not be a hardship with a flexible regimen which the patient understands. But some patients, especially when they first learn that they have diabetes, take some time to understand the principles of a diet which to the doctor seem simple enough.

Sulphonylurea tablets present little difficulty. Their toxicity is remarkably low. Their only danger, and it is small, is that they can cause hypoglycaemia. With the shortacting tolbutamide this risk is slight ; with the longer-acting chlorpropamide and acetohexamide it is a little greater. Elderly persons tolerate hypoglycaemia poorly, so it is well to guard against it. With insulin the risk is much greater. Hypoglycaemia may not be recognized as the cause of mental confusion, especially at night, in an elderly patient. These people frequently receive a long-acting insulin, such as "lente" (insulin zinc suspension) or protamine-zinc, and it is a frequent experience that these insulins may produce poor control of blood sugar during the day but lead to hypoglycaemia late at night or in the small hours. This may be a serious matter in an old person living alone. There is much to be said for treating elderly diabetics who need insulin with an intermediate type such as "semi-lente" (insulin zinc suspension [Amorphous]) or isophane (N.P.H.) insulin, and even occasionally with one injection of soluble insulin in the morning.

For those who cannot see well enough, or who have not the courage to give their own injections and cannot turn to a relative, there are various automatic devices. These are better than calling on the hard-pressed district nurse, who may not be able to get to the patient until relatively late in the morning.

The majority of elderly diabetics are women (the disease is commoner among them and they live longer than men). As they have usually married men older than themselves many elderly diabetics are widows, often living by themselves. Some need to be admitted to local-authority accommodation. A survey by the British Diabetic Association ${ }^{5}$ of nearly all local authorities in the country shows that the percentage of diabetics among the people in their welfare homes was 1.65. This indicates that local authorities are playing their part in the care of elderly diabetics. As a result of this finding the British Diabetic Association is changing its two old people's homes from long-stay residential homes to places where old diabetics can live for a few weeks, having a holiday themselves and giving their relatives a rest. This seems to be an enlightened move and is in keeping with the views of other authorities caring for elderly people. The problems of the elderly diabetic are not essentially different from those of other old people, but they are apt to be more numerous.

1 Andrews, C. T., Brit. med. F., 1957, 1, 427.

2 Redhead, I. H., ibid., 1960, 1, 695.

3 Report of a Working Party appointed by the College of General Practitioners, ibid., 1962, 1, 1497.

- Butterfield, W. J. H., Proc. roy. Soc. Med., 1964, 57, 196.

- Rogers, I. Social Welfare for the Elderly Diabetic in the United Kingdom, 1963. London, British Diabetic Association. 